\title{
IMPACTOS DA ROMANIZAÇÃO EM ALEXANDRIA: ALGUNS DEBATES BIBLIOGRÁFICOS
}

\author{
J oana Campos Clímaco* \\ joanaclimaco@hotmail.com
}

\begin{abstract}
Resumo: O objetivo do presente artigo é apresentar uma breve discussão bibliográfica sobre Alexandria quando foi sujeita ao poder romano em 31 a.C. e deixou de ser a sede do reino ptolomaico. Pretende-se destacar alguns debates historiográficos mais correntes a respeito do impacto que a "romanização" trouxe para a cidade. O novo comando representou uma ruptura ou continuidade na vida social e política da cidade? As mudanças que Augusto instituiu foram especificas para o Egito? Essas são algumas questões polêmicas que os comentadores de Alexandria têm analisado. A intenção aqui, portanto, é investigar esse novo momento da história alexandrina sob a ótica dos modernos.
\end{abstract}

Palavras-Chave: Alexandria, Egito, romanização.

A chegada de Augusto no Egito representou o fim de trezentos anos de era ptolomaica na região e formalizou seu papel como liderança única do Império, com a vitória sobre Marco Antônio. Confirmou também a anexação do Egito como província romana e Alexandria sua capital (1). Nesse momento, a cidade era já a segunda maior e mais populosa do Império. Apesar de a incorporação formal ter ocorrido apenas em 31 a.C., a aproximação com o Egito já vinha ocorrendo sutilmente desde o séc. III a.C., através de estreitas relações comerciais e diplomáticas com Roma. O último século do reinado ptolomaico foi de grande dependência da potência, o que Alan Bowman não vê como indício do declínio da dinastia, pois o Egito era um território muito atrativo pelas riquezas, e seus líderes já não tinham grandes ambições de expansão política, sendo o amigo ideal dos romanos (BOWMAN, 1994, p. 32). No entanto, a política de Cleópatra e Marco Antônio, somada às guerras civis do séc. I a.C., conseguiu adiar um pouco a sua anexação direta. A lenta

${ }^{\star}$ Doutoranda em História Social na Universidade de São Paulo. 
aproximação do Egito permitiu aos romanos um bom conhecimento das tradições milenares e de sua organização social e cultural.

O Egito deixou de ser uma unidade quase auto-suficiente economicamente e se tornou tributariamente dependente de Roma. Dessa forma, sua riqueza não mais se concentrava no território, mas saía de lá para beneficiar Roma, algo que segundo Grafton Milne já seria motivo suficiente de queixa de seus habitantes (MILNE, 1924, p. 151). Questionaremos aqui o impacto que essa mudança representou em Alexandria, como se estruturou o novo poder, de que forma foi recebido pelos alexandrinos e como o Imperador teve um papel central no seu estabelecimento. Até que ponto as medidas de Augusto "moldaram" a posição da cidade no Mediterrâneo pelos séculos seguintes? Por que Alexandria é caracterizada nos escritos antigos como uma cidade tão polêmica no Império; uma região que deveria receber um cuidado especial não só de Augusto, mas também de seus sucessores? Começaremos a análise realçando algumas reflexões historiográficas sobre as inovações políticas e institucionais trazidas à cidade, as repercussões cívicas e sociais que representaram, de que forma alteraram o modo como seus habitantes se relacionavam e como a população respondia às práticas romanas.

Enfatiza-se muito na historiografia a peculiaridade do Egito e sua importância para os romanos, o que fez com que Augusto aplicasse uma política especial e distinta das que aplicaria às outras províncias (2). Tal particularidade se deveria a alguns fatores; um deles está relacionado a sua vital importância econômica para o Império. O Egito era o maior produtor de trigo e cereais do Mediterrâneo, com a maior parte de sua produção destinada a Roma que, consequentemente, dependia dos seus produtos para sobreviver, mesmo antes da anexação da província. Alexandria tinha, assim, posição comercial central naquele universo, pela localização estratégica de seu porto, que também intensificava suas atividades econômicas. Sartre considera que os objetivos da dominação romana eram sempre os mesmos em quase todas as províncias: a exploração. No entanto, pela abundancia de riquezas do Egito, o reino era fundamental para Roma, daí o sistema de exploração ser mais rígido e complexo (SARTRE, 1994, p. 443).

Outra especificidade do Egito era o respeito imposto pela grandeza, riqueza e força de sua cultura milenar, que provocava nos antigos um misto de encanto e estranhamento, principalmente pela sua antiguidade. A "força" do território e o destaque de Alexandria foram considerados por Augusto ao estabelecer o domínio (SARTRE, 1994, p. 442). Se comparado a outras províncias, principalmente do Ocidente, o Egito tinha já uma considerável organização urbana, além de tradições culturais e religiosas muito consoli- 
dadas. Ciente disso, Augusto foi cuidadoso numa série de aspectos ao fixar seu poder no território (3).

Não apenas o Egito provocava tal encantamento, mas a própria Alexandria era admirada pela sua força cultural e riqueza de suas construções e instituições. Eleanor Huzar define a cidade no período como "a mais cosmopolita e bela do Mediterrâneo" (HUZAR, 1988, p. 624). Em virtude de sua posição litorânea e pela grande circulação de comerciantes de todas as redondezas, a exuberância do território não passou despercebida. Mesmo se comparada a Roma, no séc. I, a cidade se destacava em termos de sofisticação (4). Sua cultura e posição como centro de produção de conhecimentos eram também muito admiradas em Roma (MARLOWE, 1971, p. 214). Sarolta Takacs é ainda mais incisivo e define Alexandria como um centro cultural de dimensão tal, como Roma nunca se tornaria (TAKACS, 1995, p. 264). O interesse em toda sua riqueza cultural teria, além de tudo, finalidades práticas para os romanos, pois a cidade seria a guardiã e a ponte com o passado grego, o lugar onde todo o conhecimento antigo deveria ser acumulado e guardado, mas também mantido vivo ao alcance do Império (TAKACS, 1995, p. 271).

Grafton Milne justifica o carinho de Augusto pelo Egito por tratar-se de sua própria conquista, que marcou sua vitória sobre Marco Antônio e a consolidação de seu poder como único representante do Império (MILNE, 1924, p. 8). Mas essa justificativa parece pouco plausível perto dos outros motivos que o fariam ter cautela em relação à política destinada à cidade. A razão principal de seu cuidado parece ter sido realmente de ordem política, e se explicaria pelo temor de se organizar na cidade um núcleo de oposição formado pelos aliados do antigo rival. Antes de vencer Marco Antonio e Cleópatra, corriam rumores que a cidade estaria rivalizando com Roma e tornar-se-ia capital do 'mundo'. Para lá confluíam todas as correntes do pensamento oriental, além de sua riqueza comercial, muito mais significativa que a de Roma e da qual, inclusive, esta dependia (GRIMAL, 1993, p. 47). Essa foi uma das razões que ajudou Augusto a se tornar popular entre os romanos e vencer Marco Antônio. A relação deste com Cleópatra e seu prestígio teriam criado uma espécie de rejeição a eles, pois se acreditava que o poder do Egito poderia simbolizar uma ameaça ao desenvolvimento e expansão do Império e ao papel de Roma como sua sede (ROSTOVTZEFF, 1937, p. 103) (5).

Por todas as questões realçadas acima, Augusto temia que pudesse despertar no Egito e principalmente em Alexandria, algum foco de oposição ao Império, por ainda haver na cidade muitos partidários de seu antigo rival, 
que não seriam simpáticos ao novo líder e poderiam servir de empecilho para a concretização de seus projetos (SARTRE, 1994, p. 456; BOWMAN E RATHBONE, 1992, p. 110; MILNE, 1924, p. 121; GOODMAN, 1997, p. 265). Em virtude desse receio, a base do poder romano no Egito foi estruturada em Alexandria (MILNE, 1924, p. 120). Huzar argumenta que Cleópatra sonhava em ser a rainha de todo o Mediterrâneo, pois através de sua aliança com Marco Antônio, estava recuperando grande parte do prestígio perdido pelos últimos Ptolomeus (HUZAR, 1988, p. 348). Nesse sentido, os alexandrinos teriam desde cedo motivos para se ressentir do poder romano, em virtude da derrota de Marco Antônio ter finalizado as esperanças de a cidade se tornar a primeira do mundo, já que seus habitantes a consideravam muito superior aos romanos em tradição e cultura (WELLES, 1936, p. 8).

Temos, contudo, que ser cautelosos em simplesmente definir o Egito como uma província que teria recebido um tratamento especial do Imperador. A documentação abundante do território, referente sobretudo ao período greco-romano, nos permite acessar esferas de sua vida social, cultural e política em escala não comparável às outras províncias. Maurice Sartre acredita que grande parte da peculiaridade que comumente define o Egito é vinculada à quantidade de documentação disponível de lá, possibilitando um maior conhecimento de suas instituições (SARTRE, 1994, p. 442). Nesse sentido, Roger Bagnall considera que podemos sim usar muitas informações disponíveis a respeito do Egito para compreender práticas mais gerais da política imperial (BAGNALL, 1995, p. 66).

Augusto nomeou um administrador para a Província logo após conquistar o Egito, que residiria em Alexandria e prestaria contas a ele com grande freqüência. Instalou também no território três legiões permanentes do exército, algo também destinado especialmente à Província. Mesmo quase não sendo usada, era uma força que dificilmente passava despercebida pelos seus habitantes. No que se refere à criação de novos órgãos e às mudanças burocráticas instituídas por Augusto, muitas são as discordâncias entre os historiadores. A questão principal é: até que ponto as mudanças instituídas pelo Príncipe representaram efetivamente grandes inovações em relação ao período ptolomaico? Em suma: o que predominou foi a transformação ou a continuidade? Não cabe detalhar aqui a organização burocrática instituída pelos romanos no Egito. O objetivo é tentar entender a especificidade do momento e a recepção da população alexandrina ao poder imperial e sua estruturação na cidade. Pretendemos analisar, portanto, os elementos mais importantes no estabelecimento do novo poder, como se instalou e as respostas da população a ele, além das 
mudanças que sua imposição gerou no modo como os diversos grupos sociais se relacionavam.

Grafton Milne defende que inicialmente as mudanças instituídas foram tão sutis que a conquista romana era entendida apenas como uma alteração na Dinastia Ptolomaica (MILNE, 1924, p. 121). Isso se justificaria pela permanência de antigos cargos, funções e instituições. Alan Bowman critica essa visão argumentando que mesmo com a manutenção de muitos nomes de cargos e instituições, suas funções e a composição social dos postos administrativos mudaram radicalmente, através da infiltração de oficiais romanos nos mais diferentes setores. Assim, o Império destinaria ao Egito uma política diferenciada em relação às outras províncias. Por esse motivo, a política romana de dar continuidade a instituições e práticas de seus territórios conquistados, alterando apenas aspectos poucos aparentes, não é válida para o Egito (BOWMAN, 1986, p. 37). Sartre e Martin Goodman também acreditam que através da manutenção de postos administrativos já existentes, Augusto introduziu transformações profundas em toda a legislação e organização burocrática da Província, mudanças que permaneceriam por séculos (SARTRE, 1994, p. 456; GOODMAN, 1997, p. 265).

Por tais questões, justificar a continuidade com base na manutenção da nomenclatura pode ser complicado, pois além das re-significações de algumas estruturas de poder, as funções destinadas aos cargos e instituições não eram tão bem delimitadas e nítidas. Realiza-se aos poucos um "incremento" da burocracia provincial, sendo remanejada através da criação de novos cargos, ou alteração de algumas funções existentes e a anulação de outras. Huzar afirma que o controle foi exercido com firmeza e, por vezes, sob a superfície da tradição, tornando as inovações aparentemente suaves. Considera, contudo, as mudanças instituídas pela romanização mais marcantes que os elementos de permanência (HUZAR, 1988, p. 348 e 382).

Deve-se realçar que Roma não possuía uma política padrão de dominação e a isso se deve grande parte de suas realizações. Apesar de alguns eixos para se ordenar, grande parte da legislação destinada às províncias seria criada conforme as circunstâncias locais e a peculiaridade das estruturas de poder de cada região. Claro que muito foi alterado na execução de sua liderança no decorrer de todo o período imperial e vários fatores diferenciaram um principado do outro. Mas algumas práticas instituídas por Augusto tornaram-se uma espécie de "padrão" entre seus sucessores. Além de ter em suas mãos o poder político e administrativo supremo, o papel do Príncipe como juiz também foi crucial para estabelecer o comando. Mesmo que isso só tenha se estabelecido com mais clareza nos sécs. I e II d.C., a jurisdição 
como uma de suas funções rotineiras principais foi consolidada por Augusto (MILLAR, 1977, p. 529).

Augusto pensou no funcionamento de um sistema que nunca deixaria um único indivíduo, além do Imperador, com muito poder. Portanto, os oficiais deveriam prestar contas a ele com enorme freqüência. Assim, as funções de cada cargo não eram tão delimitadas e as esferas de atuação, muito imprecisas, fazendo com que questões burocráticas acabassem sempre voltando ao Imperador (GOODMAN, 1997, p. 109). Fergus Millar realça também em relacao às práticas imperiais como sendo caracterizadas pela flexibilidade para se estabelecer, também não se percebe um padrão para o trabalho dos imperadores. Sua administração era, em muitos momentos, passiva, e se ajustava conforme as exigências do momento e do que lhe era cobrado. Principalmente por meio da enorme quantidade de petições e embaixadas que recebia das cidades, com os mais variados propósitos (MILLAR, 1977, p. 322) (6). Bowman defende uma atuação administrativa mais ativa do soberano, pois eram seus modos de agir que definiam, dia após dia, os padrões de estabelecimento do poder (BOWMAN, 1996, p. 350). A autoridade e manifestação suprema de força era o Imperador. E para todos que estavam inseridos na sua esfera de poder, ele era visto como a personificação de toda a autoridade e representava mais do que uma mera liderança.

Além de não permitir a entrada e permanência de senadores romanos no Egito e para manter uma vigília mais rígida sobre o reino, território tão "especial" para os romanos, Augusto criou um cargo exclusivo para a Província, o de prefeito do Egito (7). Huzar acredita que a introdução do cargo foi sem dúvida a maior inovação dos romanos e o diferencial principal em relação às outras províncias (HUZAR, 1988, p. 657). A política de nomear um prefeito ao invés de senadores teria sido uma estratégia de Augusto para manter o controle mais cerrado da Província. Apesar da tentativa de aproximar a posição do prefeito à dos senadores na legislação, na prática seu comando era bem diferente (BOWMAN, 1986, p. 38). Sua autoridade variava e dependia do tipo de relação de confiança que conseguia estabelecer com o Imperador. Tal cargo era o mais elevado que se podia alcançar na ordem eqüestre, de onde o prefeito era selecionado e apontado diretamente pelo Príncipe, segundo Oscar Reinmuth principalmente por sua lealdade e habilidades administrativas (REINMUTH, 1934, p. 254). Era em certo sentido o representante pessoal do Imperador, o governante mais poderoso e sem paralelos para outras províncias (HUZAR, 1988, p. 353). O prefeito ficava no cargo em média três anos, mas esse período variou substancialmente nos dois primeiros séculos de Império e dependia de circunstâncias diversas. 
Eram selecionados para o cargo homens que deveriam ter experiência e feito carreira em outros postos oficiais, mas mesmo tendo vivência em outras funções, o prefeito não estaria necessariamente apto para governar o Egito, pois em geral eram oficiais imperiais que conheciam pouco esse território. Era desejável que tivesse algum conhecimento administrativo a respeito do território, apesar de isso não ter sido muito comum. No tempo de Augusto, a vivência militar era mais cobrada, posteriormente o mais exigido era a experiência prévia em outros cargos do Egito (BRUNT, 1975, p. 128 e129).

O prefeito deveria ter o controle sobre todos os sistemas legais do Egito, algo que na prática não se realizava com grande freqüência (HUZAR, 1988, p. 659). Por tal motivo, no início de sua administração, recebia a assistência de homens experientes nas leis locais e no começo do período imperial ainda dependia em grande medida da antiga burocracia ptolomaica. Na falta de auxiliares com experiência em assuntos legais, os prefeitos consultavam os arquivos e éditos de seus antecessores em busca de resoluções. Peter Brunt sugere que nesse processo de familiarização com a administração da Província, muitos oficiais nativos aproveitariam o desconhecimento dos novos líderes a respeito dos feitos de seus antecessores para burlar o comando em alguns setores. Portanto, o prefeito aprenderia a maior parte de suas funções na prática (BRUNT, 1975, p. 135 e 142).

Apesar de sujeito à autoridade maior do Príncipe e de contar sempre com uma grande equipe auxiliar para diferentes setores, o prefeito conquistou grande autonomia e atuação nos setores administrativos, financeiro, judicial e militar e representou uma autoridade sem equivalentes em outras regiões dominadas. Representante maior de poder no Egito, Goodman acredita que sua presença constante em Alexandria minou a cidade de suas "pretensões imperiais" (GOODMAN, 1997, p. 265). Alexandria era a residência e sede de poder do prefeito e lá passava a maior parte do seu tempo. Com alguma freqüência realizava viagens às capitais dos nomos, onde havia também representantes imperiais nas mais variadas esferas de poder e que dependiam do seu consentimento para inúmeras ações. Embora nessas áreas, principalmente nas vilas da Chora, os egípcios ainda fossem responsáveis por muitos cargos. Por tal motivo, o prefeito era também o mediador entre a população egípcia e o Príncipe, já que muitos apelos dirigidos a este eram antes encaminhados àquele, que julgava se tinham relevância a ponto de serem mandadas ao Imperador (LEWIS, 1981, p. 342).

Millar realça que a consulta constante ao soberano fazia com que, na prática, o prefeito tivesse pouca autonomia política e judicial. Mas por 
ser a autoridade maior e sempre presente na Província, cabia a ele julgar e decidir sobre eventuais conflitos e problemas na região, muitas vezes sem o consentimento do Príncipe. Em virtude dessa distância, abusos de autoridade e traição não foram incomuns dentre os prefeitos. É difícil precisar o limite entre o que ele resolvia e o que delegava a outros e tal fronteira entre questões jurídicas e civis era muito nebulosa no Egito, além da organização burocrática ser ainda pouco consistente (MILLAR, 1977, p. 324).

As autoridades romanas representavam a lei suprema, localmente na figura do prefeito e em todo o complexo administrativo, mas quando a situação demandasse, na figura do próprio Príncipe. No entanto, a cidade tinha relativa autonomia local, a qual funcionava em alguns momentos para resolver questões civis menores (MILLAR, 1977, p. 324). A possibilidade de recorrer à maior instância da lei (Imperador) era privilegio dos indivíduos os quais dispunham de maior status. Ou seja, questões cotidianas eram resolvidas pelos oficiais auxiliares e no máximo, pelo prefeito.

No que se refere à autonomia de Alexandria para demandas locais, a questão é controversa. A discussão a respeito da Boulé é um dos pontos que mais gera discórdias na historiografia sobre a cidade. A discordância é se ela a teria recebido no período ptolomaico e quais tinham sido os motivos de sua perda, pois todas as outras cidades-gregas do período dispunham da instituição, o que sugere que Alexandria também teria recebido uma Boulé de Alexandre na sua fundação.

Alguns autores defendem que a cidade tinha perdido a instituição sob os últimos reis, quando os ptolomeus começaram se envolveram em muitas disputas dinásticas e sua liderança tornou-se mais frágil. Assim, alguns alexandrinos começaram a demonstrar insatisfações em relação à autoridade real. Assim, a perda da Boulé teria sido uma espécie de "castigo" aos problemas causados pelos alexandrinos (DAVIS, 1951, p. 61; BOWMAN, 1986, p. 211; MILNE, 1924, p. 282; BELL, 1932, p. 184). Outros defendem que a cidade teria tido direito ao órgão sob os Ptolomeus e o tinha perdido no momento da chegada de Augusto, juntamente com outras mudanças instituídas na Província. Aos olhos de Grafton Milne, Augusto a teria dissolvido por temer que uma instituição como essa escapasse ao controle direto dos romanos, e pudesse representar um foco de problemas (MILNE, 1924, p. 133; FRASER, 1972, p. 93 e 94). Em troca da dissolução da Boulé e como "prêmio de consolação" pela sua perda, Augusto teria livrado os cidadãos alexandrinos do pagamento da laografia (imposto introduzido pelos romanos). Huzar acredita que a sua eliminação teria sido uma punição de Augusto aos alexandrinos por terem apoiado seu rival Marco Antônio (HUZAR, 1988, p. 
662). Contudo, é pouco provável que Augusto, ao tentar se aliar e conquistar confiança das elites alexandrinas tenha tomado uma atitude drástica como essa, que seria mais vista pela população como um castigo e não como uma medida "amigável" (8). Pelo outro lado, a perda da Boulé pode explicar grande parte dos ressentimentos dos alexandrinos ao novo poderio.

A opinião mais geral entre os historiadores é que, na fundação de Alexandria, a cidade tinha recebido a Boulé de Alexandre e a perdeu posteriormente ainda no período ptolomaico, apesar de não se saber sobre o motivo da perda. Tendo ou não sido suprimida por Augusto, o que se sabe é que a instituição só foi novamente estabelecida em Alexandria por Severo em 200/201 d.C., juntamente com outras mudanças administrativas realizadas no Egito (9). Goodman acredita que por mais que a elite grega da cidade desfrutasse de prestígio social diante dos romanos, a sua influência política foi reduzida por não disporem de uma Boulé. Tal degradação política criou um sentimento anti-romano constante nos grupos de destaque da cidade, o que contrastava com seu embelezamento e importante papel econômico, ambos no auge (GOODMAN, 1997, p. 265).

Herbert Musurillo considera que um dos maiores motivos de queixa dos alexandrinos contra os romanos, era a recusa destes na concessão de tal instituição. Assim, depois de sua conquista, as criticas ao poder imperial teriam diminuído (MUSURILLO, 1954, p. 277). No entanto, Bowman destaca que no período em que a Boulé foi finalmente concedida por Severo, ela perdera parte do seu valor político, pois até o final do séc.III encontravam-se muitos representantes imperiais na cidade, responsáveis pelo controle de sua autonomia cívica (BOWMAN, 1986, p. 212). Além disso, sua concessão nesse período pode ter gerado nos alexandrinos um sentimento duplo: por um lado estavam satisfeitos, pois a posse de uma Boulé deveria ter grande simbologia para os alexandrinos no que se refere ao retorno de sua autonomia, além do longo tempo em que justificaram a importância de sua concessão. Mas pelo outro, a sua conquista tinha sido generalizada a todas as capitais dos nomos; algo que pôde ser visto pelos alexandrinos como perda de destaque da cidade (BOWMAN e RATHBONE, 1992, p. 127). Nesse sentido, acreditamos que alexandrinos entenderam a garantia da Boulé dessa forma ambígua e ainda repleta de questionamento.

Alan Bowman e Dominic Rathbone sugerem que o vácuo causado pela ausência da Boulé em Alexandria, fez com que a elite alexandrina do Ginásio conquistasse, além de destaque no cenário cultural e social, também representatividade política, dentro da cidade e diante dos romanos (BOWMAN e RATHBONE, 1992, p. 115). O Ginásio foi uma instituição comum a 
comunidades gregas a partir do séc. III a.C., e ainda existia em praticamente todos os núcleos helenizados no período romano. Por ter sido uma criação do mundo grego, Harold Bell argumenta que no Egito o Ginásio representou o maior centro da vida cívica e de formação intelectual grega, além do maior centro de valorização dessa cultura (BELL, 1948, p. 71). Onde existia, tornou-se o maior foco de vivência social e cultural das elites gregas, o local onde esses homens se reuniam para socializar, discutir e realizar atividades intelectuais e celebrações de todo tipo (10).

No período helenístico, todo o sistema de treinamento grego de Alexandria, intelectual e físico, estava centrado no Ginásio e o acesso à instituição era aberto ao setor helenizado da população, inclusive àqueles que não possuíam a cidadania hereditária. O treinamento no Ginásio e na efebéia era também um dos critérios essenciais para a obtenção da cidadania alexandrina (FRASER, 1972, p. 77). Fraser argumenta que, no séc. III a.C., o corpo de cidadãos era basicamente composto de gregos, os quais ainda não tinham perdido seus vínculos com a terra-mãe. No séc. II, ele já era formado pelos descendentes desses gregos e era essa elite hereditária que teria representado a elite alexandrina de mais poder e prestígio no período romano. O grupo do Ginásio começou a preencher o "vácuo cultural” deixado pelo declínio da imigração de intelectuais para a cidade, que se iniciou no período de crise da Dinastia Ptolomaica, paralelamente à ascensão de Roma como potência (FRASER, 1972, p. 78).

O líder da instituição, o ginasiarca, contribuía com generosas somas destinadas ao seu funcionamento e o cargo lhe conferia honras litúrgicas e grande respeitabilidade, além de pouca responsabilidade administrativa (HUZAR, 1988, p. 661). A entrada no Ginásio era restrita e garantida aos membros que pudessem demonstrar a ascendência grega do lado paterno e materno. A menção aos ginasicarcas é mais freqüente que alusões ao funcionamento do Ginásio, e mesmo com relação ao cargo, é mencionado muito mais como indicativo de status do que para explicar precisamente suas funções e atividades (CRIBIORE, 2001, p. 36).

Raffaella Cribiore destaca que nas cidades do Egito em que o Ginásio existia o acesso aos postos mais altos da instituição era privilégio de homens com níveis educacionais elevados e se destacariam na vida pública de suas cidades. Nesse sentido, a "vivência intelectual" desses homens letrados se voltava para a discussão de questões de ordem prática. Ou seja, já tinham passado por todos os níveis educacionais mais elementares, se familiarizado com o cânone literário grego e alcançado o estágio da eloqüência e da retórica, concedendo ao homem poder, riqueza, fama e acesso à vida pública (CRI- 
BIORE, 2001, p. 221 e 224). Bagnall acredita que apesar do esforço para se conservar nesses círculos o cânone grego tradicional, novos gêneros literários estavam sempre sendo criados, além da redefinição e novas interpretações de textos antigos (BAGNALL, 1993, p. 103). Contudo, Cribiore enfatiza que a educação da elite helenística era ainda muito semelhante em todo o Mediterrâneo, criando um forte elo de comunicação entre os que a recebiam. Apesar de influenciada por outras tradições, as quais a diversificaram numa série de aspectos, o cânone de textos era ainda muito arraigado no passado grego e raramente aceitava novidades literárias do período (CRIBIORE, 2001, p. 247). Principalmente em Alexandria, pela importância do Museu e da Biblioteca, grande parte da produção, difusão e sobrevivência da literatura do mundo greco-romano só pôde ocorrer graças à sua produção na cidade (BOWMAN, 1986, p. 232). Assim, os cidadãos que tinham recebido esse tipo de educação reforçariam constantemente a sua tradição cultural antiga.

Os cidadãos do Ginásio eram os habitantes de maior destaque e status em Alexandria, e se consideravam os mais prejudicados com a conquista romana, pois muitos dos seus antigos privilégios foram perdidos. Assim, atuaram em muitos momentos como foco de resistência aos novos dirigentes (DELIA, 1991, p. 106). Além de serem os maiores críticos dos romanos, eram também os elementos de mais voz na cidade e, consequentemente, tinham mais possibilidade de acesso ao Príncipe. Importantes questões cívicas eram decididas no Ginásio: quando embaixadas e petições eram enviadas ao Imperador, comumente os seus membros eram os escolhidos para se posicionar diante dos romanos, já que não eram apenas homens letrados, mas também versados em retórica (MILLAR, 1977, p. 8). O sucesso ou fracasso de uma embaixada dependia muito da elaboração dos discursos pronunciados (DELIA, 1991, p. 385). No entanto, tal grupo também tinha muitos compromissos com os romanos, pois num primeiro momento, os tinham auxiliado no estabelecimento do poder. Ou seja, os romanos confiavam nesses alexandrinos como aliados para instituir o comando na Província (TCHERIKOVER, 1963, p. 4).

Além das inovações em todo o complexo burocrático do Egito, outra grande transformação instituída pelos romanos foi a introdução de censos, que definiria o status dos indivíduos e repercutiria diretamente na cobrança de impostos, nesse momento realizada através do sistema de coleta direta. Resultante da sistematização de novos critérios foi redigido o Gnomon do Idios Logos (Select Papyri II, 206). Huzar o define como o código financeiro instituído por Augusto para o pagamento dos impostos (HUZAR, 1988, p. 360). Através dessa sistematização, os romanos aumentaram o número 
de categorias populacionais e complexificaram o aparato burocrático para determinar o status dos indivíduos, o que deveria desencorajar a mobilidade social (HUZAR, 1988, p. 631). A demarcação era essencial para o funcionamento da estrutura do governo. De acordo com Diana Delia, os romanos articularam o sistema de forma a delimitar muito bem as fronteiras referentes a um e outro grupo, dificultando enormemente a entrada dos que estavam fora. Mas os que possuíam status mais baixo se utilizavam de várias estratégias para tentar ultrapassar as fronteiras e elevar sua posição (DELIA, 1991, p. 36 e 38).

Tal inovação acabou simplificando algumas de suas definições étnicas para que a identificação diante dos romanos ficasse mais fácil, o que foi feito sem considerar todas as implicações e a variedade dos aspectos culturais de cada grupo. Victor Tcherikover argumenta que os romanos adotaram estratégias para classificar os habitantes do Egito como "gregos" ou "nãogregos”. Dessa forma, os princípios para separá-los foram estabelecidos segundo critérios artificiais, acabando por classificar como "gregos" muitos cidadãos que tinham se helenizado, mas não eram helenos por ascendência (TCHERIKOVER, 1963, p. 4).

Os únicos isentos da laografia eram os gregos que tinham a cidadania alexandrina, algo possível apenas aos que comprovassem a ascendência grega, o antigo vínculo com a cidade e a inserção nos círculos culturais helenizados. Nem toda a população grega de Alexandria possuía a cidadania e com os romanos a sua concessão ficou mais restrita. Fora do núcleo helenizado o acesso era ainda mais rígido; alguns poucos judeus e egípcios de postos mais elevados parecem tê-la conquistado, mas para isso deveriam se inserir, de alguma forma, nesses círculos. Nesse sentido, o vinculo hereditário com os cidadãos alexandrinos era o pré-requisito maior para a obtenção da cidadania, algo que os gregos tentariam sempre comprovar. Habitantes helenizados das outras cidades gregas do Egito também estavam sujeitos ao pagamento da laografia, mas a uma menor taxa que egípcios e judeus. Com isso, tais elites começaram a adquirir destaque diante dos romanos, algo antes restrito apenas às provenientes de Alexandria. Reforçando o controle dessas definições, os egípcios foram deixados num patamar abaixo dos que estavam inseridos no universo cultural grego (BOWMAN, 1986, p. 125). Dessa forma, os romanos reforçaram ainda mais os direitos das elites de maior distinção e sua herança helenística.

Como vimos, a variedade populacional da cidade foi um elemento marcante desde a sua fundação. No entanto, teve repercussões substancialmente diferentes no período ptolomaico e romano. Se a definição de "ser 
grego" era algo difuso em Alexandria no seu contexto de fundação, essa demarcação tornou-se ainda mais complexa, pois passadas diversas gerações desde a sua composição social inicial, a configuração dos grupos e o tipo de vínculo que eles estabeleceriam com a cidade e com seus vizinhos muito já tinha se alterado. Além disso, Alexandria era "amadurecida" o suficiente para ter criado alguma cultura própria, mesmo sendo em certa medida resultante de toda a diversidade que a compôs inicialmente. E devido à convivência com outras culturas, os elementos que em alguma medida serviam para "unificar" a cultura grega já tinham perdido muita força. O que ocorreu foi uma tentativa de revalorizar tais elementos e "resgatá-los" do seu desaparecimento. Dessa forma, apesar das disputas, rivalidades e aspectos culturais próprios das diversas comunidades de origem helênica, ainda existia uma "unidade" que se baseava na língua, tradição e interesses comuns (MARLOWE, 1971, p. 20).

Os não-gregos, egípcios e estrangeiros de territórios não helenizados, eram considerados os habitantes de menor status e, consequentemente, estavam sujeitos às maiores cobranças (apesar da obtenção da cidadania por uma minoria). Eram considerados egípcios todos os elementos provenientes da Chora, e de outras regiões do Egito. Nas capitais dos nomos também se destacavam grupos de nativos helenizados, porém em relação aos das cidades gregas eles não tinham a mesma influência e eram considerados de status inferior, portanto, pagavam maiores impostos em relação aos gregos de Alexandria. Além disso, muitos que tinham emigrado para Alexandria eram designados pelos de lá como egípcios (apesar de serem substancialmente helenizados). Os judeus também receberam maiores cobranças que os de origem helênica, o que os deixou num patamar aproximado ao dos egípcios e foi considerado por eles como maior motivo de insatisfação frente ao poderio imperial e aos vizinhos alexandrinos.

Acreditamos que grande parte da insatisfação dos alexandrinos com os romanos se refere a tais medidas, pois, nessa simplificação, as categorias que não tinham muita importância para o Império ainda poderiam dispor de grande valor entre eles. Ou seja, a distinção da cultura alexandrina e de quem tinha possibilidade de adquira-la deveria ser responsabilidade dos próprios alexandrinos e não ser definido por critérios impostos de fora. Observa-se então que a romanização era sentida através de modificações, aparentemente sutis, que poderiam, contudo, significar muito para a tradição dos provinciais e a sua formação cultural. E se a intenção dos romanos era, através disso, se aliar às elites locais, nem sempre alcançaram tal propósito. Nesse sentido, talvez a mudança de maior impacto imposta pelo Império, 
que trouxe repercussões mais evidentes para as relações sociais da população alexandrina, tenham sido as novas definições de status.

Devemos observar, ainda, que nenhuma das categorias sociais aqui definidas era homogênea e a assimilação e aproximação entre as diversas culturas ocorriam em todos os momentos, apesar da criação de "barreiras" entre elas (algumas permanentes e outras mais flexíveis de acordo com as circunstâncias). Gregos e judeus, por exemplo, se identificavam linguisticamente, já que o grego era a língua oficial dos dois grupos, no entanto, cultural e religiosamente muito os distinguia. Egípcios e gregos, pelo outro lado, tinham uma religiosidade muito mais "conciliável" e puderam ajustar suas crenças em algumas ocasiões e criar cultos comuns. Nesse sentido, apesar de alguns elementos das duas tradições religiosas causarem estranhamento mútuo, no geral, não eram significativos a ponto de impedirem a tolerância na vivência diária de seus grupos.

Em termos demográficos, Diana Delia apresenta algumas possibilidades referentes à Alexandria (DELIA, 1988, p. 273). Ela ressalta que os números apresentados por Fílon e Flávio Josefo são provavelmente exagerados, porém tendo em vista a precariedade das evidências arqueológicas da cidade, eles devem sim ser considerados (11). Levando em conta a escassez da documentação referente a tais números, e considerando a expansão da cidade durante o período romano, Delia não acredita que a sua população total tenha ultrapassado os 600 mil, dos quais aproximadamente trezentos mil seriam cidadãos. No entanto, não se sabe ao certo se todos residiam na cidade ou se estavam apenas registrados. O número é muito incerto e aproximado, pois além dos problemas referentes às fontes, muitas pessoas poderiam ter a cidadania alexandrina, mas não residir na cidade.

Com relação à comunidade judaica, deve-se ressaltar a sua dimensão no período romano, chegando a representar quase $1 / 3$ da população alexandrina, além de ser a maior da Diáspora. Alguns judeus tinham recebido a cidadania no contexto de fundação da cidade, enquanto a maioria não obteve o acesso, restrito apenas aos judeus mais ricos, influentes e que tinham conquistado algum espaço no universo grego. A peculiaridade do judaísmo em relação aos gregos e egípcios se deve ao seu corpo de leis e doutrinas, que obrigava o fiel a ter uma rotina diferente de toda a população da cidade, pois suas crenças incidiam diretamente sobre o seu comportamento diário. Para os outros estrangeiros, era mais fácil se inserir numa nova sociedade e ao mesmo tempo praticar suas tradições antigas. Para os judeus, isso era mais difícil, já que os preceitos de sua religião não diziam respeito apenas à fé, mas a todo o modo de se comportar e se organizar, mesmo abrindo mão 
de certas práticas mais ortodoxas. Claro que o judaísmo da Diáspora não era homogêneo, como também não era o grau de aceitação da cultura helênica e a aculturação. Além disso, com a distância de Jerusalém, as escrituras deixaram margem para diversas interpretações e formas de perceber a religião.

De modo geral, os judeus da Diáspora encontraram nas suas crenças, nas sinagogas e na união, baseada na identificação mútua, as formas de propagar sua fé, já que estavam distantes do Templo e da "matriz" de sua religiosidade, Jerusalém. A comunidade de Alexandria era substancialmente helenizada, mas mesmo assemelhando-se culturalmente aos gregos em muitos sentidos, os judeus ainda conviviam mais entre si, e criavam uma espécie de "barreira" em relação aos gentios. Apesar da tentativa de separação de outros grupos, John Collins argumenta que, sobretudo para os judeus mais eruditos e das classes abastadas, a inserção na cultura helênica era antes de tudo uma questão de "sobrevivência". Assim, continuavam a praticar a antiga fé, mas de forma que facilitasse a convivência com estrangeiros. Ou seja, renunciavam a algumas práticas que os isolavam e os separavam dos não-judeus (como a observância do sábado e a circuncisão) e reafirmavam as quais legitimassem sua fé diante dos gentios, e que a transformassem em algo simpático ou ao menos indiferente a estes (COLLINS, 2000, p. 169). Nesse sentido, a lei era observada seletivamente e adaptada ao contexto helenístico (COLLINS, 2000, p. 155).

John Barclay considera a correta observância das leis como o fator que mantinha a comunidade judaica unida, tornando seu modo de vida distinto da comunidade dos gentios, apesar de em determinados momentos fazerem um uso menos rígido das mesmas (BARCLAY, 1996, p. 426). Tais barreiras criadas pelo respeito às leis era o que os conservava unidos e vulneráveis aos olhos de não-judeus. Estes por vezes, as consideravam anti-sociais e hostis, sobretudo quando elas interferiam em outros setores do cotidiano (12). Observa-se então, um judaísmo "transformado", que tentava articular uma ética comum e aceitável a diversas tradições e culturas. Assim, adotavam muitos aspectos do helenismo, através de uma "roupagem" grega em diversos setores, para se fazer compreender por eles e justificar a eles sua própria crença (COLLINS, 2000, p. 275).

É interessante analisar a produção literária do judaísmo da Diáspora, pois está constantemente se utilizando de artifícios para, ou se fazer entender pelos gregos e conquistar a simpatia deles pelo seu modo de vida, ou encorajando os judeus a observar a fé, num ambiente onde renunciar a isso é algo propício. A Septuaginta, por exemplo, a tradução da Torá para o grego foi produzida em Alexandria, colocou os gentios em contato com a fé judaica, 
algo mais difícil anteriormente. A nova versão foi recebida provocando nos núcleos helênicos sentimentos mistos de curiosidade, admiração, estranhamento e aversão (BARRACLOUGH, 1984, p. 437).

A comunidade judaica era não só privilegiada economicamente, mas também influente na vida política da cidade, principalmente no período helenístico (TCHERVIKOVER, 1963, p. 1). A princípio, a maioria dos judeus apoiou a dominação romana, pois acreditou que seus privilégios anteriores seriam confirmados. Com Augusto, isso se concretizou. No entanto, a política romana de reforçar o elemento grego e aliar-se a tais elites para consolidar suas conquistas, foi degradante para os judeus. Pois dessa forma, tiveram o status igualado ao dos egípcios no pagamento das taxações, dos quais os alexandrinos estavam isentos.

Apesar das queixas dos judeus, no que se refere ao pagamento de impostos, os imperadores romanos, como os Ptolomeus anteriores, permitiam que vivessem de acordo com suas leis e costumes antigos. Nos Principados de Augusto e Tibério, a situação foi relativamente tranqüila, mas com Calígula os problemas se intensificaram, pois ameaçou a continuidade da observância da fé judaica. Os alexandrinos se aproveitaram da oposição do Imperador para também manifestar suas insatisfações contra o grupo. Ocorreu então, em 38, o primeiro conflito aberto entre os grupos. Fílon, historiador judeu de Alexandria, descreve a polêmica como um "ataque" dos gregos sobre os judeus, que teriam sido as completas vítimas da situação. O autor relata detalhadamente as violências de que os judeus foram vítimas. Além do desrespeito ao templo, a população alexandrina também protestava contra o direito judaico de obtenção da cidadania e da participação política, além de os proclamarem estrangeiros no território egípcio (In Flaccum 55-57). Depois da revolta, embaixadas dos dois partidos se dirigiram a Calígula para disputar seus direitos. O relato de tal embaixada está no outro livro de Fílon que nos interessa mais diretamente, o Legatione ad Gaium. Além de narrar os eventos, Fílon foi o representante da embaixada do lado judaico (13).

Podemos perceber que a situação entre os grupos se agravou principalmente no Principado de Calígula: o primeiro Imperador a ameaçar a continuidade da prática da fé judaica. Os alexandrinos se aproveitaram da oposição do Príncipe para protestar contra direitos políticos que eles estariam adquirindo. A partir daí, episódios de conflitos ocorreram com grande freqüência, e os protagonistas foram geralmente os dois grupos. No ano em que assumiu o Império, Cláudio escreveu uma carta aos alexandrinos com o objetivo de colocar um fim às turbulências de maneira diferente de seu antecessor, tentando conciliar os interesses dos dois grupos, mas deixando 
claro que considerava os judeus estrangeiros em Alexandria (14). Na Guerra dos Judeus, Flávio Josefo relata as desordens tinham se tornado universais no período do embate e os conflitos antigos entre os grupos de Alexandria tinham se acirrado ainda mais. $\mathrm{O}$ autor narra mais um conflito ocorrido no reinado de Nero, que teria começado com uma pequena disputa no anfiteatro dos gregos, tendo, contudo, alcançado grandes dimensões (15). Barclay sugere que no período da guerra da Judéia (entre 66 e 73 d.C.), os judeus da Diáspora perderam muito da "boa reputação" diante dos romanos, além da destruição do Templo, que abalou a moral do judaísmo de maneira geral (BARCLAY, 1996, p. 75 e 76).

A tensão entre os grupos foi uma constante a partir do reinado de Calígula e as manifestações contrárias ao judaísmo cresceram progressivamente entre os alexandrinos. Deve-se ressaltar, contudo, que os relatos a respeito das revoltas do séc. I são provenientes de Josefo e Fílon, ambos judeus que preservavam boas relações com os romanos. Nesse sentido, os judeus são sempre descritos como completas vítimas de conspiração por parte dos alexandrinos.

O último grande conflito de que se tem notícia entre os dois grupos ocorreu no reinado de Trajano (115-117 d.C.). O conflito se iniciou em Cirene como uma revolta dos judeus contra os romanos e seus vizinhos helenizados, mas atingiu o Egito e tomou grandes proporções em Alexandria, até que a comunidade judaica foi praticamente dizimada da cidade (16).

Segundo Ellen Birnbaum, os alexandrinos censuravam à passividade com que os judeus se comportavam diante dos governantes romanos. $\mathrm{Ou}$ seja, os gregos, por enfatizarem sempre a autonomia política, estavam mais aptos a enfrentar seus dirigentes. Por outro lado, os judeus não tinham pretensões políticas e geralmente se contentavam em poder praticar suas antigas tradições. Assim, eram facilmente submetidos e, constantemente se tornavam protegidos de seus dirigentes e os auxiliavam em inúmeros aspectos (BIRNBAUM, 2004, p. 114). Alston sugere que a situação que levou os alexandrinos ao anti-judaísmo foi uma criação romana, ao reforçar o caráter grego da cidade e lhes deixar ter o domínio administrativo (ao aceitar o poder político do Ginásio) (ALSTON, 1997, p. 172 e 173).

Em relação aos egípcios, a situação era um pouco diferente. A camada sacerdotal se beneficiou em inúmeros setores e foi muito favorecida pelos dirigentes romanos. Apesar de o demótico (língua egípcia) predominar nesses círculos, muitos membros do núcleo sacerdotal tinham aprendido o grego e, mesmo fora do grupo, era mais comum aos egípcios o aprendizado do grego do que o contrário. E se comparado a outras culturas, os egípcios 
eram mais dispersos em Alexandria e não parecem ter desenvolvido nenhuma coesão e unidade forte (como os judeus) (HUZAR, 1988, p. 634). Além disso, grande parte da cultura egípcia antiga foi adotada pelos gregos, permitindo que muitas práticas dos dois grupos fossem mais conciliáveis. Ou seja, era comum perceber indivíduos “indecisos" entre os dois mundos, sendo que acabavam até se inserindo, em alguns setores como gregos, e em outros, como egípcios (BOWMAN, 1986, p. 63). Já foi dito acima que dentre os últimos Ptolomeus, quando o poder da Dinastia estava enfraquecendo, a cultura egípcia passou a ser mais valorizada. Nesse sentido, a helenização dos egípcios e a entrada de alguns nos círculos "predominantemente gregos" passou a ser mais aceita (MARLOWE, 1971, p. 106).

A peculiaridade do poder romano com relação a governos estrangeiros anteriores era a sua tolerância cultural e religiosa com os povos dominados. Assim, a observância de antigos cultos e tradições culturais eram aceitas, contanto que não tivesse repercussões políticas maiores, ou seja, que não interferisse na estrutura de poder imperial. Se os romanos tinham o intuito de enfraquecer algum culto ou manifestação local, os artifícios para tal eram muito sutis. No geral, isso parece ter funcionado e ter sido a "essência" da romanização nas províncias. Ou seja, os imperadores não tinham a intenção de impor nenhum tipo de ideologia (social, política ou religiosa), o objetivo era evitar dissidências internas e manter as províncias pacíficas, daí a força permanente do exército caso a ordem fosse ameaçada (GOODMAN, 1997, p. 81).

Deve-se ressaltar que a maior inovação do período imperial foi a centralização política de um enorme complexo territorial nas mãos de um só homem, uma unidade política em escala nunca antes vista. Claro que a diversidade dos povos era ainda visível, embora parte tenha sido "englobada" culturalmente pelos valores helenísticos. Nesse sentido, os romanos tiveram que criar um sistema que pudesse preservar a diversidade cultural, mas que politicamente abarcasse todos numa única esfera de poder. O Imperador e seu modo de se relacionar com os provinciais tiveram, portanto, papel central e ativo nesse processo.

Ellen Birnbaum acredita que mesmo que já existisse em Alexandria estranhamento e até algum tipo de hostilidade entre os grupos sociais, dificilmente tinham sido suficientes para resultar em conflitos ou discordâncias maiores. Foram as questões políticas e sociais responsáveis por tornar as diferenças mais evidentes e acabaram por resultar em problemas maiores (BIRNBAUM, 2004, p. 160). Sob a mesma perspectiva, Bowman salienta que apesar dos sinais claros de distinção na religiosidade entre os grupos no período romano, a diversidade não tinha sido a causa real de tensão em 
circunstâncias normais, apesar de em alguns momentos ter sido o meio através do qual as tensões foram expressas (BOWMAN, 1986, p. 179). Mesmo sendo realmente os aspectos culturais e religiosos os elementos de mais distinção entre os grupos, no geral, eles souberam conciliar seus costumes e estabelecer diálogos entre suas tradições. Ou seja, se as insatisfações tinham raízes religiosas e culturais, só se manifestaram com mais força quando alcançaram dimensões civis, políticas e sociais. E mais: tais diferenças raramente resultavam em conflitos abertos, mas se expressavam comumente através da escrita ou de maneiras mais simbólicas.

Apesar da transformação política e dos problemas que começaram a surgir entre alexandrinos e judeus, de forma geral, a situação dos grupos diante dos romanos foi relativamente pacífica no séc. I a.C. Rostovtzeff argumenta que apesar da perda de autonomia e da importância cultural da cidade, principalmente no período júlio-cláudio, o desenvolvimento econômico foi seguido de um renascimento cultural, pois os imperadores dessa casa tinham em alta estima a cultura grega, daí a consideração especial pela população helenizada das cidades gregas (ROSTOVTZEFF, 1937, p. 231). Consequentemente, Alexandria manteve o seu "movimento científico" e os imperadores ainda protegiam e estimulavam a produção dos membros do Museu, apesar da instituição ter começado a se destacar mais como um centro de ensino que de pesquisa (EL-ABBADI, 1993, p. 94 e 95). Alan Bowman argumenta que no Egito do séc. I d.C. estabilidade econômica e o aumento das atividades comerciais foram importantes por permitirem uma "despolitização" da Província, a que se soma a presença permanente de uma frota no território, o que foi suficiente para manter a população "calma" (BOWMAN, 1986, p. 40).

Bowman define Alexandria como a maior "realização" dos gregos no Egito, pois na maior parte do tempo a cidade se manteve isolada dos problemas maiores dos reinos helenísticos, e depois foi ainda protegida pela "penumbra" da paz romana. Ou seja, foi materialmente enriquecida e culturalmente não teve grandes rivais, por ser a "líder" da tradição literária e intelectual grega. Com tudo isso, Alexandria conquistou a liberdade e o estímulo para se desenvolver numa cidade espetacular, a "verdadeira rainha do Mediterrâneo" (BOWMAN, 1986, p. 204). Martin Goodman argumenta que apesar das diversas inovações terem ajudado a cidade a enriquecer e se desenvolver em inúmeros aspectos, a nova situação começou a ser lentamente sentida pelas suas elites intelectuais. Muitas das mudanças não foram bemrecebidas e começaram a nutrir nesses grupos um sentimentos mistos em relação ao novo poderio, que as vezes se manifestariam e tomariam a forma 
de resistência ao Império (GOODMAN, 1997, p. 265). Macmullen realça que, geralmente, os grupos anti-imperiais eram nobres que se afastavam e discordavam dos romanos apenas em momentos isolados, por terem muito a perder. Não eram "classes" que se opunham, daí a cautela nas manifestações. Estas não se expressavam como resistência ao domínio romano como um todo, mas apenas a pessoas específicas (MACMULLEN, 1992, p. 94). A repressão ou favorecimento do Imperador a um grupo variava de acordo com o interesse imperial do período (HAAS, 1997, p. 81).

Da mesma forma que os romanos eram, em muitas ocasiões, sutis em se impor, as maneiras de resistir aos imperadores também eram cuidadosas e dificilmente ditas publicamente. Eram, sobretudo, expressas na forma escrita, pois a audiência pretendida era a de homens letrados e das classes superiores. Assim, tinham ideais mais simbólicos que subversivos. Ou seja, a escrita era usada como forma de se expressar através da memória, com a finalidade de relembrar e imortalizar certos episódios (MACMULLEN, 1992, p. 36). Alan Bowman e Greg Woolf ressaltam a importância da escrita em "comunidades textuais" da Antiguidade, que serviram para reforçar a união de certos grupos, encorajando a identidade coletiva dos mesmos, para assim, conquistar legitimidade em situações de "dominação" (BOWMAN e WOOLF, 1998, p. 19). Sem desconsiderar a força do exército romano, sabemos que apenas ele não teria possibilitado tamanha conquista. Assim, dirigentes imperiais tiveram que se utilizar de inúmeras formas de propaganda para afirmar sua expansão. Nesse sentido, notam-se formas de reagir à dominação através de escritos com tom de propaganda. Desse modo, a tradição cultural grega de tentar demonstrar sua hegemonia pela literatura e retórica foi perceptível nesse momento, pois buscava alcance intelectual entre os letrados, algo que John Marlowe definiu como "politicamente conservador e intelectualmente subversivo” (MARLOWE, 1971, p. 25).

A sociedade romanizada tinha consciência do poder da escrita como sinalizador e gerador de mudanças. A tentativa de expandir alguma ideologia privilegiava a palavra escrita, apesar de a habilidade discursiva ainda ser mais valorizada (WOOLF, 2000, p. 879). No entanto, o modo de manifestar críticas era muito considerado pelas elites provinciais, já que, em muitos aspectos, elas "lucravam" com o sistema romano e se tinham críticas a ele, eram geralmente parciais e, por isso, expressas de forma cautelosa. Assim, muitas vezes manifestavam a insatisfação de maneira simbólica (GOODMAN, 1997, p. 162).

Nos séculos I e II, a repressão dos romanos às manifestações de resistência ao Império era mais rígida, pela expansão não ter se encerra- 
do, além da consolidação do poder romano em algumas áreas ser ainda frágil. Nesse sentido, a "censura" contra quem ameaçasse a estabilidade de opiniões era dura. Huzar argumenta que, aos poucos, Alexandria "perde o seu brilho" e autonomia e começa a "existir prioritariamente para servir o seu mestre" (HUZAR, 1988, p. 668). Sobretudo no séc. II d.C. isso ficou mais nítido, pois além da maior decadência cultural do período, há sinais de que o enriquecimento estava ficando mais lento (MILNE, 1928, p. 56 e 57). No séc. III, as atitudes repressivas começaram a diminuir e se tornar menos eficazes, consequentemente as críticas ao poder romano passaram a ser mais toleradas (MACMULLEN, 1992, p. 156). E mais: a política romana de promover a urbanização em cidades de pouco desenvolvimento cívico fez com que as capitais dos nomos começassem a se destacar também através de instituições tipicamente gregas. Tal situação fez com que Alexandria já não tivesse tanto destaque em relação às outras cidades do Egito, e nem tanta influência diante dos imperadores. Por isso, a insatisfação ao Império se torna mais comum. Michael Rostovtzeff realça que "a nova realidade" era sentida pelos alexandrinos como sinal de decadência em relação à antiga posição de relevo de Alexandria, já que ela se assemelharia cada vez mais a outros centros urbanos que estavam emergindo (ROSTOVTZEFF, 1937, p. 244). Acreditamos, então, que esse foi o período mais apropriado para manifestar algum tipo de reação às práticas imperiais, pois além de todas as circunstâncias já realçadas acima, haveria mais facilidade de expor insatisfações aos novos líderes. O séc. III se caracteriza, ainda, por um momento de maior "incremento" na burocracia das províncias, e por uma crise generalizada no Império (econômica e política) (BELL, 1948, p. 193).

Mais um episódio pode ter estimulado o intuito de criticar os romanos nesse período e ter sido recebido como uma espécie de "gota d'água", que desagradou a população frente aos dirigentes. Trata-se do massacre dos alexandrinos por Caracala ocorrido em 215 (o episódio é narrado por Herodiano e Dion Cássio). O motivo teria sido algum episódio de ridicularização do Imperador promovido na cidade, devido à sua "mania" de se comparar à Alexandre, além de sátiras produzidas sobre a morte de seu irmão (17). Relata-se que a destruição na cidade foi ampla, e as medidas instituídas pelo Príncipe após os problemas se estenderam à cidade como um todo (tropas permanentes de vigília na cidade, abolição de órgãos públicos, etc.). Convencido de que a intelectualidade da cidade estava por trás da rebelião, Caracala interrompeu também o patrocínio imperial ainda investido no Museu, diminuindo ainda mais a imigração de homens ilustrados para a 
cidade, fazendo enfraquecer consideravelmente a efervescência de sua vida intelectual (GOODMAN, 1997, p. 268). Assim, tantas mudanças instituídas em Alexandria, vindas "de fora para dentro", podem ter sido consideradas como afrontas para os alexandrinos.

Vimos então que nos dois primeiros séculos de Império, Alexandria era vista pelo poder romano como um território já propenso a desordens e tumultos, pela fama de seus cidadãos se rebelarem facilmente. E em virtude de tantos problemas entre alexandrinos e judeus, as atenções das lideranças imperiais estavam firmemente voltadas para a cidade. Paralelamente a isso, tratava-se de um território muito respeitado, pela sua grandeza e riqueza, mas também pela força de sua intelectualidade e produção cultural, que concedia aos grupos de destaque possibilidades de prestígio e distinção nos círculos de saber, e também chances de acesso às instâncias máximas do poder romano. Muitos representantes de tais elites tinham se aliado aos romanos e os auxiliado no estabelecimento de poder, pois deles conseguiam privilégios e também desejavam garantir os que já tinham. No entanto, vários eventos e problemas pontuais faziam os alexandrinos recorrer constantemente aos oficiais romanos, uma lembrança de que a liderança suprema não mais se encontrava em seu solo, e diante disso, precisavam da intromissão externa para resolver seus problemas internos. Nesse sentido, se muitos aprovavam o poder romano e lucravam com ele, outros tinham posições indecisas em relação ao novo comando, e estavam com freqüência se questionando e ponderando sobre o tipo de vivência imposto por e esperada dos alexandrinos.

\section{ImPACTS OF ROMANIZATION tO AlEXANDRIA: a FEW BIBLIOGRAPHICAL DEBATES}

AвSTRACT: The aim of the present article is to present a brief bibliographic discussion concerning Alexandria when it became subject to the Roman Power in 31 b.C., ending its role as the capital of the Ptolemaic reign. The intention is to bring up a few more common historiographical discussions about the impact that "Romanization" brought to the city. Did the new command represent continuity or a break in the city's social and political life? Were the changes introduced by Augustus specific for Egypt? These are a few polemic issues that historians who study Alexandria have been analyzing; therefore the objective here is to investigate this new moment in the Alexandrian history through the eyes of the moderns.

KeY-Words: Roman Alexandria, roman Egypt, Romanization. 
NOTAS

1 Sobre a chegada de Augusto, Estrabão relata: "O Egito é agora uma província; e não apenas paga tributos consideráveis, mas é também governado por homens prudentes - os prefeitos, que são para lá enviados de tempos em tempos. Agora esse enviado tem o status de rei; e subordinado a ele está o administrador de justiça, que tem autoridade suprema sobre a maior parte do conjunto de leis; e outro é o oficial chamado Idiologo, que investiga em todas as propriedades aquelas que estão sem proprietário e que devem ser transferidas para César; e estas também são acompanhadas de libertos de César, e também por auxiliares, a quem são confiados assuntos de importância média. Há também três legiões de soldados, das quais uma está colocada na cidade e as outras no campo. [...] Estes oficiais existiam também no tempo dos reis, mas como os reis estavam realizando um mau governo, a prosperidade da cidade estava também desaparecendo por prevalecer a desordem." (Estrabão. Geografia 17. 1. 12). Tradução a partir do inglês de Horace Leonard Jones.

2 Alan Bowman é o maior defensor dessa visão.

3 Sobre o "cuidado" de Augusto com o Egito, Dion Cássio relata: “[...] e no caso dos egípcios e alexandrinos, ele poupou todos eles, para que nenhum perecesse. A verdade é que ele não considerou apropriado infligir algum dano irreparável sobre um povo tão numeroso, que poderia se provar muito útil aos romanos de várias formas; contudo, como pretexto para mostrar sua bondade ele fez oferendas à sua divindade Serápis, ao seu fundador Alexandre, e em terceiro lugar, ao seu cidadão Areius, cujo aprendizado e companhia ele mesmo desfrutou." (Dion Cássio. História Romana 51, 3-4). Tradução a partir do inglês de Earnest Cary.

4 Dion Crisótomo, ao polemizar sobre o "caráter" da população alexandrina, promove diversos elogios à cidade e realça sua superioridade em relação às outras pelo seu tamanho e poder, o que a situa em segunda posição entre as cidades mais importantes do Império. Mas destaca que seus habitantes não faziam jus à sua grandeza e virtuosidade, pela falta de auto-controle. (Dion Crisóstomo. 32. 35-40). E apesar de terem "homens tão razoáveis como governantes, causastes um sentimento suspeito em relação a vocês e os fizeram acreditar que era necessário ter mais vigilância que anteriormente”. (Dion Crisóstomo. 32. 71) Tradução a partir do inglês de J.W. Cohoon.

5 Dion Cássio relata a respeito do poder e fascínio que Cleópatra exercia sobre Marco Antônio, que chegou ao ponto de escrever em seu testamento que desejava ser enterrado em Alexandria ao lado da rainha. Tal fato teria deixado os romanos tão indignados, pois isso era uma prova de que se ele tivesse a oportunidade, 
transferiria o poder central para o Egito. Dion relata que isso acabou com sua popularidade e mesmo seus amigos o censuraram por tal atitude e o privaram de seu consulado e de toda a sua autoridade como general. (Dion Cássio. História Romana 50. 3-5).

5 A importante obra de Millar, The Emperor in the Roman World realça o papel central do imperador durante todo o Principado, mas também caracteriza a sua liderança como passiva, no sentido de ter firmado o seu comando geralmente em resposta às demandas do momento e ao que lhe era cobrado e pedido, p. 412.

6 Sobre as mudanças instituídas no Egito, Dion Cássio relata: “Depois ele tornou o Egito tributário e deu a sua liderança à Cornélio Gallus. Pois em virtude da populosidade das cidades e do campo, e pelo caráter superficial e inconstante de seus habitantes, e pela extensão de seu fornecimento de grãos, ele não ousou confiar o território a nenhum Senador, e nem sequer concedeu que senadores lá morassem, a não ser que ele pessoalmente fizesse a concessão no seu próprio nome... (Dion Cássio. História Romana 51,17.). Tradução a partir do inglês de Earnest Cary.

7 Dion Cássio não menciona a eliminação da Instituição, mas relata a negação de Augusto à sua concessão, como se observa no seguinte trecho: “[...] ele comandou os alexandrinos a conduzirem seu governo sem senadores; pela sua capacidade para a revolução, que eu imagino, ele atribuiu a eles. E do sistema então imposto a eles, muitos detalhes são rigorosamente preservados no tempo presente, mas eles têm seus senadores tanto em Alexandria, o que começou sob o imperador Severo, quanto em Roma, que foram inscritos no Senado pela primeira vez no reino do filho de Severo, Antonino.". (Dion Cássio. História Romana 51. 17). Tradução a partir do inglês de Earnest Cary.

8 Há menção a tal questão na História Augusta, no relato sobre Severo: "Ele então concedeu aos alexandrinos o privilégio de um senado local, pois eles ainda estavam sem nenhum conselho público, da mesma forma que estavam sob seus antigos reis, e foram obrigados a se contentar com um governante único apontado por César. Além disso, ele mudou muitas de suas leis. Depois de anos Severo constantemente declarava que tinha achado essa viagem muito proveitosa, pois ele tinha participado da adoração à divindade Serápis, tinha aprendido algo sobre antiguidade, e tinha visto animais não familiares e lugares estranhos. Pois visitou Mênfis, Memnon, as Pirâmides e o Labirinto, e examinou todos eles com muito cuidado." (História Augusta. Severo 17. 2-4). Tradução a partir do ingles de David Magie.

9 Com relação ao Ginásio de Alexandria, Estrabão relata: "Em suma: a cidade é repleta de estruturas públicas e sacras; mas a mais linda é o Ginásio, que pos- 
sui pórticos com mais de um estádio de comprimento". (Estrabão. Geografia 17.10.10). Tradução a partir do inglês de Horace Leonard Jones.

10 Era prática comum entre os historiadores de a Antiguidade exagerarem seus números, geralmente no que se refere ao volume de mortos em guerras e à população de determinados locais. Faziam isso provavelmente para transformar seus relatos em novidades, e para superarem seus antecessores no fantástico.

11 De acordo com a argumentação de Fredrik Barth, é o estabelecimento dessas fronteiras que caracteriza uma etnia. As distinções étnicas não pressupõem uma ausência de mobilidade, contato e informação, mas categorias discretas mantêm e perpetuam essas barreiras, mesmo que a interação cultural entre os grupos seja intensa e se caracterize por uma aceitação mútua. As diferenças culturais se manifestam através, justamente, da estruturação de barreiras sutis. No que se refere ao judaísmo, a argumentação de Barth muito explica o porquê de eles serem habitantes de terras estrangeiras há séculos, mas mesmo assim serem considerados pelos não-judeus como estranhos naquela terra. Além disso, por mais que eles tentassem um maior desprendimento das tradições mais ortodoxas e a aproximação dos outros grupos, ainda existiam fronteiras que os distinguiam e faziam com que eles convivessem mais entre si. As fronteiras não eram inalteráveis e alheias às mudanças na sociedade global, mas tinham que se adequar às mudanças do meio externo. Conferir: Frederik Barth. "Grupos étnicos e suas fronteiras" in: Phillipe Poutignat e Jocelyne Streiff-Fenart (eds.). Teorias da etnicidade. São Paulo: UNESP, 1998. P. 188.

13 A maior parte da narrativa é dedicada a descrever às insanidades cometidas pelo Imperador, que começou a agir muito estranhamente depois do sétimo mês do seu reinado, acometido por uma doença causada pela excessiva dedicação aos "prazeres mundanos", que o faria ter pretensões divinas e os judeus eram os únicos que se negavam a adorá-los dessa forma. (Fílon. Legatione ad Gaium 18 e 19). Fílon profere um discurso em que enfatiza que menos importante do que os problemas políticos em Alexandria era a ameaça à continuidade da observância de sua religiosidade conforme suas leis antigas. $\mathrm{O}$ autor realça que o que deveria ter sido um julgamento, foi na verdade um teatro em que os atores eram os alexandrinos e o próprio Calígula, situação que ajudou a acelerar a decadência dos judeus em Alexandria (Fílon. Legatione ad Gaium 29). Flávio Josefo relata a mesma embaixada e diz que três delegados de cada facção foram escolhidos para se apresentarem diante de Calígula. Calígula os trata de uma forma "excessivamente raivosa" e deixou claro que deles se vingaria por não o aceitarem como deus. (Josefo. Antiguidades Judaicas 18. 257- 260). 
14 É interessante citar aqui o trecho em que Cláudio se refere aos problemas entre os dois grupos: "[...] embora eu esteja mantendo comigo um "estoque" de imutável indignação contra qualquer partido que renovar o conflito; e lhes aviso de uma vez por todas para colocar um fim nessa prejudicial e obstinada inimizade recíproca. [...] Por isso, novamente eu lhes evoco para que, por um lado os alexandrinos se mostrem indulgentes e bondosos diante dos judeus que por tanto tempo moram na mesma cidade, e não desonrem nenhum dos seus ritos observados por eles em adoração ao seu deus, mas permita que eles observem seus costumes como no tempo de divino Augusto, costumes os quais eu também, depois de ouvir os dois lados, sancionei; e pelo outro lado eu ordeno explicitamente que os judeus não insistam por mais privilégios que tiveram anteriormente, e que no futuro não mandem embaixadas separadas como se morassem numa cidade diferente, algo sem precedentes, e que não forcem a entrada nos jogos do ginásio ou cosméticos, enquanto aproveitam seus próprios privilégios e participam de uma grande abundância de vantagens numa cidade que não é a deles [...] caso contrário eu irei por todos os meios me vingar deles como fomentadores de uma grande praga geral que infesta o mundo inteiro." (Carta de Cláudio aos alexandrinos. Select Papyri II.) Tradução a partir do inglês de A.S. Hunt e C.C. Edgar.

15 Por ocasião de uma embaixada que os alexandrinos tinham enviado a Nero, os judeus entraram no anfiteatro, o que os alexandrinos entenderam como intrusão e se apressaram à expulsa-los de lá. A maioria dos judeus fugiu, mas três foram queimados vivos. Nesse momento, toda a população judaica se manifestou em defesa dos mortos e o conflito tomou conta do anfiteatro. O prefeito Tibério Alexander tentou interromper a disputa ainda sem o uso de armas e os avisaram para não provocar o exercito romano, mas os conflitantes não o levaram a sério. Seus pedidos não surtiram efeito, o que o fez pedir auxílio às duas legiões romanas (que ficavam permanentemente na cidade), além de dois mil soldados. As tropas mataram os revoltantes, queimaram suas casas e ainda se dirigiram ao bairro dos judeus, o Delta, e os massacraram. Josefo detalha a violência que sofreram, dizendo que os romanos não teriam poupado nem as crianças, e que no final havia pilhas de corpos por todos os lados, chegando o número de mortos a alcançar os 50 mil. Nesse momento, o prefeito teve compaixão e mandou os romanos pararem com o massacre, estes o interromperam imediatamente, mas a população alexandrina, devido à "intensidade de seu ódio não se desencorajou assim tão facilmente”. (Josefo. Guerra dos Judeus 2. 487-498).

16 A revolta é narrada por Dion Cássio (Dion Cássio. História Romana 68. 32) e Eusébio (Eusébio. História Eclesiástica 4.2). Eusébio realça que nesse período os 
sofrimentos dos judeus chegaram ao seu clímax, destruindo uma grande multidão deles. Em Alexandria e no resto do Egito e especialmente em Cirene, eles foram tomados por "um terrível espírito de rebelião" contra seus vizinhos gregos. A rebelião se expandiu no ano seguinte tomando a forma de uma grande guerra, quando Lupus era o governante do Egito. Ela se iniciou em Cirene, sob a liderança de um tal Lucuas e atingiu uma enorme proporção, tomando Alexandria e todo resto de Egito, chegando inclusive a alcançar a Mesopotâmia. Dion Cássio afirma que o tal líder que os judeus teriam escolhido como rei para liderar a revolta se chamava Andréias (e não Lucuas) e realça que os judeus estavam destruindo tanto romanos quanto gregos, $\mathrm{o}$ autor descreve ainda mais detalhadamente as violências cometidas e salienta que no final o número de mortos chegou a quase 220 mil pessoas.

17 Herodiano relata que em sua expedição pelo Oriente, Caracala ( 215 d.C.) partiu de Antioquia para Alexandria com o pretexto de conhecer a cidade fundada em honra de Alexandre e de sacrificar ao deus pelo qual os cidadãos de lá tinham uma veneração especial (Seráfis). A razão de sua indignação a eles era por ter recebido em Roma, no tempo de vida de seu irmão, e mesmo depois de seu assassinato, muitos relatos de que os alexandrinos o estariam desrespeitando. Caracala então, se aproveitou da ocasião e participou das festividades. Quando ele percebeu que a cidade estava lotada e tinha reunido o povo de todos os distritos ao redor, ele emitiu um decreto de que todos os homens jovens deveriam se reunir em assembléia num lugar aberto para promover uma homenagem a Alexandre. Depois de passar por todas as filas e se certificar que todos estavam cercados, como animais presos numa armadilha, ele sutilmente saiu de lá com seu exército pessoal, enquanto isso seu exército massacrou todos os homens que ali estavam. Alguns da tropa promoviam a matança, enquanto outros escavavam buracos para jogar os mortos em pilhas e enterrá-los, sendo que muitos foram lá jogados e enterrados vivos. A matança foi tão grande que o vale do Nilo e grande parte do litoral ficaram vermelhos de sangue. (Herodiano. 4.8-9) Dion Cássio salienta que apesar da afeição de Caracala por Alexandre, ele destruiu toda a população da cidade fundada por ele e depois ainda aboliu os espetáculos e encontros públicos dos alexandrinos e ordenou que a cidade fosse dividida por um muro e ocupada por guardas com certa freqüência, para que os alexandrinos não se visitassem e nem se reunissem mais. (Dion Cássio. História Romana 78. 22-24).

\section{REFERÊNCIAS}

ALSTON, Richard. Philo's 'In Flaccum': Ethnicity and Social Space in Roman Alexandria. Greece and Rome 44, p. 165 -175, 1997. 
BAGNALL, Roger S. Reading Papyri, Writing Ancient History. London/New York: Routledge, 1995.

BARCLAY, John. Jews in the Mediterranean Diaspora - From Alexander to Trajan (323 BCE - 117 CE). Berkeley / Los Angeles/ London: University of California Press, 1996.

BARRACLOUGH, Ray. Philos' politics, Roman rule and Hellenistic Judaism. In: TEMPORINI, Hildegard e HAASE, Wolfgang. Aufstieg und Niedergang der Römischen Welt II.21.1, p. 417-553, 1984.

BARTH, Fredrik. Grupos étnicos e suas fronteiras. In: POUTIGNAT, Phillipe e STERIFF-FENART, Jocelyne (eds.). Teorias da etnicidade. São Paulo: UNESP, 1998.

BELL, Harold, I. The Problem of the Alexandrian Senate. Aegyptus 12, p. 173-184, 1932. Press, 1948.

Egypt from Alexander the Great to the Arab conquest. Oxford: Claredon

BIRNBAUM, Ellen. Portrayals of the Wise and Virtuous in Alexandrian Jewish Works: Jews' Perceptions of Themselves and Others. In: HARRIS, William V. e RUFFINI, Giovanni (Eds.). Ancient Alexandria between Egypt and Greece. Leiden/ Boston: Brill, 2004.

BOWMAN, Alan K. e RATHBONE, Dominic. Cities and Administration in Roman Egypt. The Journal of Roman Studies 82, p. 107-127, 1992.

BOWMAN, Alan K. e WOOLF, Greg. Cultura escrita e poder no mundo antigo. São Paulo: Editora Ática, 1998.

BOWMAN, Alan K. Papyri and Roman Imperial history: 1960-75. Journal of Roman Studies 66, p. 153-73, 1976.

. Egypt after the Pharaos 332 B.C. -A.D.642. California: University of California Press, 1986.

. Egypt. In: BOWMAN, Alan K.; CHAMPLIN, Edward, LINTOTT, Andrew.

The Cambridge Ancient History. Second Edition. Vol. 10. Cambridge: Cambridge University Press. 1996. Pp. 676-702.

BRUNT, Peter A. The administrators of Roman Egypt. In: Journal of Roman Studies 65, p. 124-47, 1975.

COLLINS, John J. Between Athens and Jerusalem. Jewish Identity in the Hellenistic Diaspora. Michigan: Eerdmans, 2000.

CRIBIORE, Raffaella. Gymnastics of the mind - Greek Education in Hellenistic and Roman Egypt. New Jersey: Princeton University Press, 2001.

DAVIS, Stuart. Race-relations in Ancient Egypt: Greek, Egyptian, Hebrew, Roman. London: Methuen \& Co. Ltd., 1951. 
DELIA, Diana. The population of Roman Alexandria. Transactions of the American Philological Association 118, p. 273-92, 1988.

. Alexandria Citizenship during the Roman Principate. Atlanta: Scholars Press, 1991.

EL-ABBADI, Mostafa. The Alexandrian citizenship. Journal of Egyptian Archaeology 48, p. 106-23, 1962.

. Alexandria: Thousand-Year Capital of Egypt. In: STEEN, Gareth L. (ed.) Alexandria: The Site and the History. New York/ London: New York University Press, 1993.

FRASER, Peter M. Ptolomaic Alexandria I-III. Oxford: Clarendon Press, 1972.

GOODMAN, Martin. The Roman World. 44BC - AD180. London / New York: Routledge, 1997.

GRIMAL, Pierre. O Império Romano. Lisboa: Edições 70, 1993.

HAAS, Christopher. Alexandria in Late Antiquity: Topography and Social Conflict (Ancient Society and History). Baltimore / London: The Johns Hopkins University Press, 1997.

HUZAR, Eleanor G. Alexandria ad Aegyptum in the Julio-Claudian Age. In: HAASE, Wolfgang e TEMPORINI, Hildegard. (eds.) Aufstieg und Niedergang der Römischen Welt II.10.1. Berlin/ New York: Walter de Gruyter, p. 619-668, 1988.

Augustus, Heir of the Ptolemies. In: HAASE, Wolfgang e TEMPORINI, Hildegard. (eds.) Aufstieg und Niedergang der Römischen Welt II.10.1. Berlin/ New York: Walter de Gruyter, p. 343-382, 1988.

LEWIS, Naphtali. On Judicial Appeals in Roman Egypt. The American Journal of Philology 102, p. 340-343, 1981.

Press, 1983.

Life in Egypt under Roman rule. Oxford/ New York: Oxford University . Greeks in Ptolomaic Egypt. Case studies in the Social History of the Hellenistic World. Oakville, Connecticut: American Society of Papyrologists, 2001.

MACMULLEN, Ramsay. Enemies of the Roman order. London/New York: Routledge, 1992.

MARLOWE, John. The Golden Age of Alexandria. London: Victor Gollancz, 1971.

MILLAR, Fergus. The emperor in the roman world: $31 B C-A D$ 337. London: Duckworth, 1977.

MILNE, Grafton. Egyptian Nationalism under Greek and Roman Rule. Journal of Egyptian Archaeology 14, p. 702-742, 1928. . A History of Egypt under Roman Rule. London: Methuen \& Co., 1924. 
MOMIGLIANO, Arnaldo. Os limites da Helenização. A interação cultural das civilizações grega, romana, céltica, judaica e persa. Rio de Janeiro: Jorge Zahar, 1991. MUSURILLO, Herbert. Acts of the Pagan Martyrs. New York: Oxford University Press, 1954.

REINMUTH, Oscar W. The Edict of Tiberius Julius Alexander. Transactions and Proceedings of the American Philological Association 65, p. 248-259, 1934.

ROSTOVTZEFF, Michael I. Historia Social y Econômica del Império Romano. 2 vols. Madrid: Espasa-Calpe, S.A., 1937.

SARTRE, Maurice. El Oriente Romano. Provincias y sociedades provinciales del Mediterráneo Oriental. De Augusto a los Severos (31a.C.-235 d.C.). Madrid: Akal Ediciones, 1994.

TAKACS, Sarolta. A. Alexandria in Rome. Harvard Studies in Classical Philology 97, p. 263 - 276, 1995.

TCHERIKOVER, Victor. The decline of the Jewish Diaspora in Egypt in the Roman Period. The Journal of Jewish Studies 14, p. 1-32, 1963.

WOOLF, Greg. Literacy. In: BOWMAN, Alan K.; GARNSEY, Peter e RATHBONE, Dominic. The Cambridge Ancient History. Vol. XI. Cambridge: Cambridge University Press, p. 875-897, 2000.

WELLES, Charles B. A Yale Fragment of the Acts of Appian. Transactions of the American Philological Association 67, p. 7-23, 1936. 